\title{
Article
}

\section{Investigation of the thermal decomposition and flammability of PEEK and its carbon and glass-fibre composites}

Patel, Parina, Hull, T Richard, Lyon, Richard E., Stoliarov, Stanislav I., Walters, Richard N., Crowley, Sean and Safronava, Natallia Available at http://clok.uclan.ac.uk/1917/

Patel, Parina, Hull, T Richard ORCID: 0000-0002-7970-4208, Lyon, Richard E., Stoliarov, Stanislav I., Walters, Richard N., Crowley, Sean and Safronava, Natallia (2011) Investigation of the thermal decomposition and flammability of PEEK and its carbon and glass-fibre composites. Polymer Degradation and Stability, 96 (1). pp. 12-22. ISSN 01413910

It is advisable to refer to the publisher's version if you intend to cite from the work. http://dx.doi.org/10.1016/j.polymdegradstab.2010.11.009

For more information about UCLan's research in this area go to http://www.uclan.ac.uk/researchgroups/ and search for <name of research Group>.

For information about Research generally at UCLan please go to http://www.uclan.ac.uk/research/

All outputs in CLoK are protected by Intellectual Property Rights law, including Copyright law. Copyright, IPR and Moral Rights for the works on this site are retained by the individual authors and/or other copyright owners. Terms and conditions for use of this material are defined in the policies page. 


\title{
Investigation of the Thermal Decomposition and Flammability of PEEK and its Carbon and Glass-Fibre Composites
}

\author{
Parina Patel ${ }^{\mathrm{a}}$, T. Richard Hull ${ }^{\mathrm{*}^{*}}$, Richard E. Lyon ${ }^{\mathrm{b}}$, Stanislav I. Stoliarov ${ }^{\mathrm{c}}$, Richard \\ N. Walters ${ }^{b}$, Sean Crowley $^{b}$ and Natallia Safronava ${ }^{d}$ \\ ${ }^{a}$ Centre for Fire and Hazards Science, School of Forensic and Investigative Science, University Of \\ Central Lancashire, Preston, PR1 2HE, UK \\ ${ }^{\mathrm{b}}$ Fire Safety Branch, Federal Aviation Administration, William J. Hughes Technical Centre, Atlantic \\ City International Airport, NJ 08405, USA \\ ${ }^{c}$ Department of Fire Protection Engineering, University of Maryland, MD 2042, USA \\ ${ }^{\text {d }}$ SRA International, Inc., 1201 New Road, Linwood NJ 08211, USA
}

\begin{abstract}
Conventional thermally durable materials such as metals are being replaced with heat resistant engineering polymers and their composites in applications where burn-through resistance and structural integrity after exposure to fire are required. Poly aryl ether ether ketone (PEEK) is one such engineering polymer. Little work has been published with regards to the flammability of PEEK and its filled composites. The current study aims to assess the flammability and fire behaviour of PEEK and its composites using thermogravimetric analysis, pyrolysis combustion flow calorimetry, limiting oxygen index, a vertical flame resistance test, and fire (cone) calorimetry.
\end{abstract}

1. Introduction

Applications in which polymers are replacing traditional materials are on the increase. In many cases, polymers and their composites are now being used where the fire risk scenario is dissimilar to any encountered previously. In addition to ignition resistance and low heat release rate, engineering polymers may now be required to resist burn-through and maintain structural integrity whilst continuing to provide fire protection when exposed to fire or heat.

Aryl poly ether ether ketone (PEEK) is an engineering thermoplastic first introduced by Imperial Chemical Industries (ICI) in 1978 [1]. Its excellent thermal, chemical and mechanical properties have allowed for its use in a variety of high performance applications: the polymer has recently been adopted in the aviation and automotive industries where conventional thermally durable materials, such as metals, are being replaced by lighter weight, high thermal stability polymers [2] [3] [4]. To date, little work has been published on the flammability of poly(aryletherketones) with more attention assigned to the material's thermal [5] [6] [7] [8] [9] [10] [11] and thermo-kinetic properties [12] [13] [14] [15] [16] [17] [18] [19]. As a result of the increased interest in engineered polymers such as PEEK and its composites, robust flammability data is necessary for applications requiring lightweight fire performance.

\footnotetext{
* Corresponding author. Tel: +44 (0)1772 893543. Fax: +44 (0)1772 894981

E-mail: trhull@uclan.ac.uk
} 
PEEK's excellent thermal properties are attributed to the stability of the aromatic backbone comprising the bulk of the monomer unit, shown in Figure 1.<smiles>CC(C)(C)C(=O)c1ccc(Oc2ccc(Oc3ccc(C(F)(F)F)cc3)cc2)cc1</smiles>

Figure 1. Repeat Unit of Poly(oxy-1,4-phenyleneoxy-1,4-phenylenecarbonyl-1,4-phenylene) (PEEK)

Semi-crystalline PEEK has a glass transition temperature $\left(T_{g}\right)$ of $143^{\circ} \mathrm{C}$, a continuous use temperature of $260^{\circ} \mathrm{C}$, a melting point $\left(\mathrm{T}_{\mathrm{m}}\right)$ of $343^{\circ} \mathrm{C}$ and an onset of decomposition temperature between 575 and $580^{\circ} \mathrm{C}[20]$ and thus, is one of the most thermally stable thermoplastic polymers available.

Techniques employed for measuring the ignition and burning behaviour of a polymer are numerous. Fire tests in common use aim to determine the following properties of materials [21]:

- Ease of ignition

- Rate of flame spread

- Rate of heat release

- Ease of extinction

- Smoke/Toxic gas evolution

Of those listed, many authors argue that the single most important parameter for determining a materials' fire hazard is its heat release rate (HRR) [22] [23] as this, together with the rate of surface flame spread will determine the fire growth rate. As direct determination of heat release rate is practically problematic, this parameter is typically determined on an oxygen consumption calorimetry basis: the approximation that $13.1 \mathrm{~kJ}$ of energy is produced per gram of oxygen consumed [24]. Two methods for measuring heat release rate effectively are the Cone Calorimeter and Pyrolysis Combustion Flow Calorimeter (PCFC). Developed in 1982, [25] the Cone Calorimeter has become one of the most important and widely used instruments for the research and development of fire retardant polymeric materials. The PCFC was developed in 1999 [22] [26] by researchers of the Federal Aviation Administration (FAA) as a tool to assist in the flammability assessment of milligram-sized samples. Recent correlations between the two methods have been established [27] [28]. Heat release rates determined by the PCFC and cone calorimeter provide information on oxygen consumption at micro and bench scales, respectively.

Other parameters such as flame spread and ease of extinction are commonly determined in smallflame flammability tests such as the UL-94 and Limiting Oxygen Index (LOI), respectively. In addition, thermogravimetric analysis (TGA) can provide information on the thermal stability of a material in both oxidative and inert atmospheres. Mass loss in air primarily reflects the thermal-oxidative decomposition processes occurring at the surface prior to ignition whereas an inert atmosphere, such as nitrogen, is representative of the fuel gas production below the surface and after ignition, as the concentration of oxygen under a flame is close to zero [29].

This study assesses the flammability behaviour of PEEK and two composites containing carbon and glass fibre in order to characterise their fire behaviour.

\section{Experimental}

\subsection{Materials}


The samples of PEEK used in this study were supplied by Victrex plc and were semi-crystalline ( $35 \%$ crystallinity as measured by Differential Scanning Calorimetry (DSC)) Victrex PEEK ${ }^{\mathrm{TM}}$ grades $450 \mathrm{G}$, $450 \mathrm{CA} 30$ and 450GL30. The unfilled 450G polymer has a molecular weight of approximately 100000 $\mathrm{g} \mathrm{mol}^{-1}$. The 450CA30 and 450GL30 are reinforced grades of the 450G PEEK containing 30 percent (\%) carbon and glass fibre by weight, respectively. 450CA30 contains carbon fibres derived from polyacrylonitrile (PAN) with a length of $\sim 200 \mu \mathrm{m}$ and diameter of $7 \mu \mathrm{m}$. 450GL30 contains glass fibres with a length of $\sim 200 \mu \mathrm{m}$ and diameter of $10 \mu \mathrm{m}$. Both carbon and glass fibres are incorporated for added strength, stiffness and dimensional stability. All materials are available commercially.

\subsection{Thermogravimetric Analysis}

Thermal decomposition was investigated by thermogravimetric analysis (TGA) in an inert atmosphere using a Mettler Toledo TGA/SDTA 851. Measurements were performed on samples of $10 \mathrm{mg}( \pm 0.5 \mathrm{mg})$ under a nitrogen atmosphere with a heating rate of $10^{\circ} \mathrm{C} \mathrm{min}^{-1}$ and flow rate of 35 $\mathrm{ml} \mathrm{min}^{-1}$. Thermal analysis in air was undertaken using a TA Instruments Q500 TGA. Sample weight was $10 \mathrm{mg}( \pm 5 \mathrm{mg})$ with a heating rate of $10^{\circ} \mathrm{C} \mathrm{min}^{-1}$ and an air flow rate of $35 \mathrm{ml} \mathrm{min}^{-1}$.

\subsection{Pyrolysis Combustion Flow Calorimeter}

Small-scale flammability tests were carried out on the Federal Aviation Administration's Pyrolysis Combustion Flow Calorimeter and samples were tested in triplicate according to ASTM D7309-07 [30]. Samples were $5 \mathrm{mg}( \pm 0.5 \mathrm{mg})$ in weight and were obtained from the centre of the cone calorimeter plaques detailed below. The heating rate was $60^{\circ} \mathrm{C} \mathrm{min}^{-1}$ in an $80 \mathrm{~cm}^{3} \mathrm{~min}^{-1}$ stream of nitrogen; the maximum pyrolysis temperature was $900^{\circ} \mathrm{C}$. The anaerobic thermal degradation products in the nitrogen gas stream were mixed with a $20 \mathrm{~cm}^{3} \mathrm{~min}^{-1}$ stream of oxygen prior to entering the combustion furnace at $900^{\circ} \mathrm{C}$. The heat release was determined by oxygen consumption calorimetry.

\subsection{Limiting Oxygen Index}

The flammability, characterised by the ability of a material to sustain candle-like burning, was determined using the FTT Limiting Oxygen Index apparatus according to ISO 4589-2 [31], using injection moulded samples with the following dimensions: $125 \times 10 \times 4 \mathrm{~mm}$.

\subsection{Underwriters Laboratory Vertical Test for Flammability of Plastics UL-94 V}

The ignitability and flame spread were determined using the standard UL-94 vertical burn test according to BS 60695-11-10 [32]. Injection moulded samples were $125 \times 13 \times 3 \mathrm{~mm}$. As a UL-94 V-0 rating for 450G, 450CA30 and 450GL30 has already been obtained, the results were recorded to compare the burn lengths and times for each material. Ten samples of each material were examined.

\subsection{Fire (Cone) Calorimetry}

A Fire Testing Technology (FTT) Cone Calorimeter was utilised to characterise forced flaming behaviour following the procedure outlined in ASTM D1354-04a. [33]. Sample dimensions were 100 $\times 100 \times 2.5 \mathrm{~mm}$ and all materials were tested in triplicate in the horizontal orientation. An irradiance of $50 \mathrm{~kW} \mathrm{~m}^{-2}$ was used. 
3. Results and Discussion

3.1 Thermogravimetric Analysis

Anaerobic Thermal Decomposition in Nitrogen

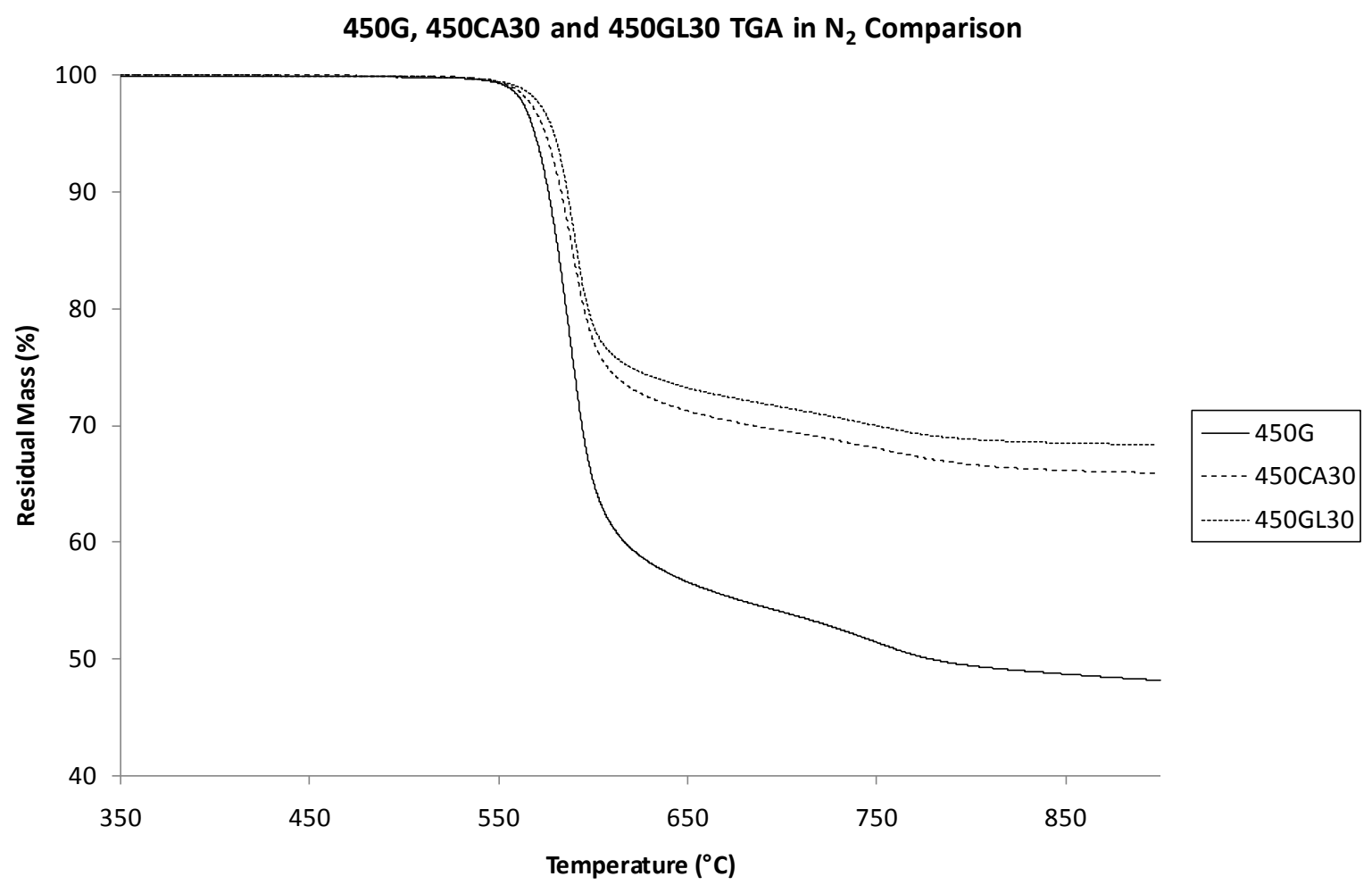

Figure 2. TGA in $\mathrm{N}_{2}$ Data for $450 \mathrm{G}, 450 \mathrm{CA} 30$ and $450 \mathrm{GL} 30$

Samples of 450G, 450CA30 and 450GL30 were analysed in an inert atmosphere in the TGA and averaged data for the triplicate analyses are shown in Figure 2. Thermal decomposition of PEEK begins at around $555^{\circ} \mathrm{C}$ which is much higher than for most polymers. Thermal decomposition is a two-step process, with the first step of thermal decomposition centred at $585^{\circ} \mathrm{C}$ and attributed to the random chain scission of the ether and ketone bonds [18] [34] [35]. The second decomposition step occurs above $600^{\circ} \mathrm{C}$, and is attributed to the cracking and dehydrogenation of the crosslinked residue produced in the first stage of decomposition and results in a thermally stable carbonaceous char [20]. The $10 \%$ mass loss temperature of $450 \mathrm{G}$ occurs between 570 and $580^{\circ} \mathrm{C}$. Interestingly, $30 \%$ of the loss in the first stage of decomposition occurs within a $30^{\circ} \mathrm{C}$ window, and is complete after a $40 \%$ mass loss. There is no obvious component within PEEK's structure which corresponds to a $40 \%$ mass loss. The second stage only loses $10 \%$ of the original mass up to $900^{\circ} \mathrm{C}$, giving a $50 \%$ char yield. There is little further loss after $800^{\circ} \mathrm{C}$; and at $900^{\circ} \mathrm{C}$ the material appears stable. Scission and release of both the ether and ketone groups would result in $21 \%$ weight loss, based on the repeat unit of PEEK. $40 \%$ weight loss indicates that some aromatic compounds are also being released as products - possibly in the form of phenol, observed in pyrolysis gas chromatography-mass spectrometry (pyGC-MS) as a major decomposition product of PEEK [9].

For the filled materials, 450GL30 has a slightly higher onset of decomposition temperature than 450CA30; both have a higher onset temperature than 450G. 450CA30 and 450GL30 show a similar 
first stage of decomposition resulting in around $23 \%$ weight loss. It may be assumed that a process occurs at $600^{\circ} \mathrm{C}$ which either delays $450 \mathrm{GL} 30$ decomposition or accelerates $450 \mathrm{CA} 30$ decomposition. After $600^{\circ} \mathrm{C}$, both materials enter the second stage of decomposition with $450 \mathrm{CA} 30$ continuing to decompose at a faster rate than $450 \mathrm{GL} 30$. After $800^{\circ} \mathrm{C}$, little weight loss is observed and the final mass of material remaining for $450 \mathrm{CA} 30$ and $450 \mathrm{GL} 30$ is $65 \%$ and $68 \%$, respectively, which is slightly higher than the sum of the mass fractions of the inert filler and the char fraction of the PEEK matrix. In an inert atmosphere, the presence of filler increases the thermal stability of pure PEEK and 450GL30 appears to be the more thermally stable of the fibre-filled materials.

Thermal Oxidative Decomposition in Air

450G, 450CA30 and 450GL30 TGA Air Comparison

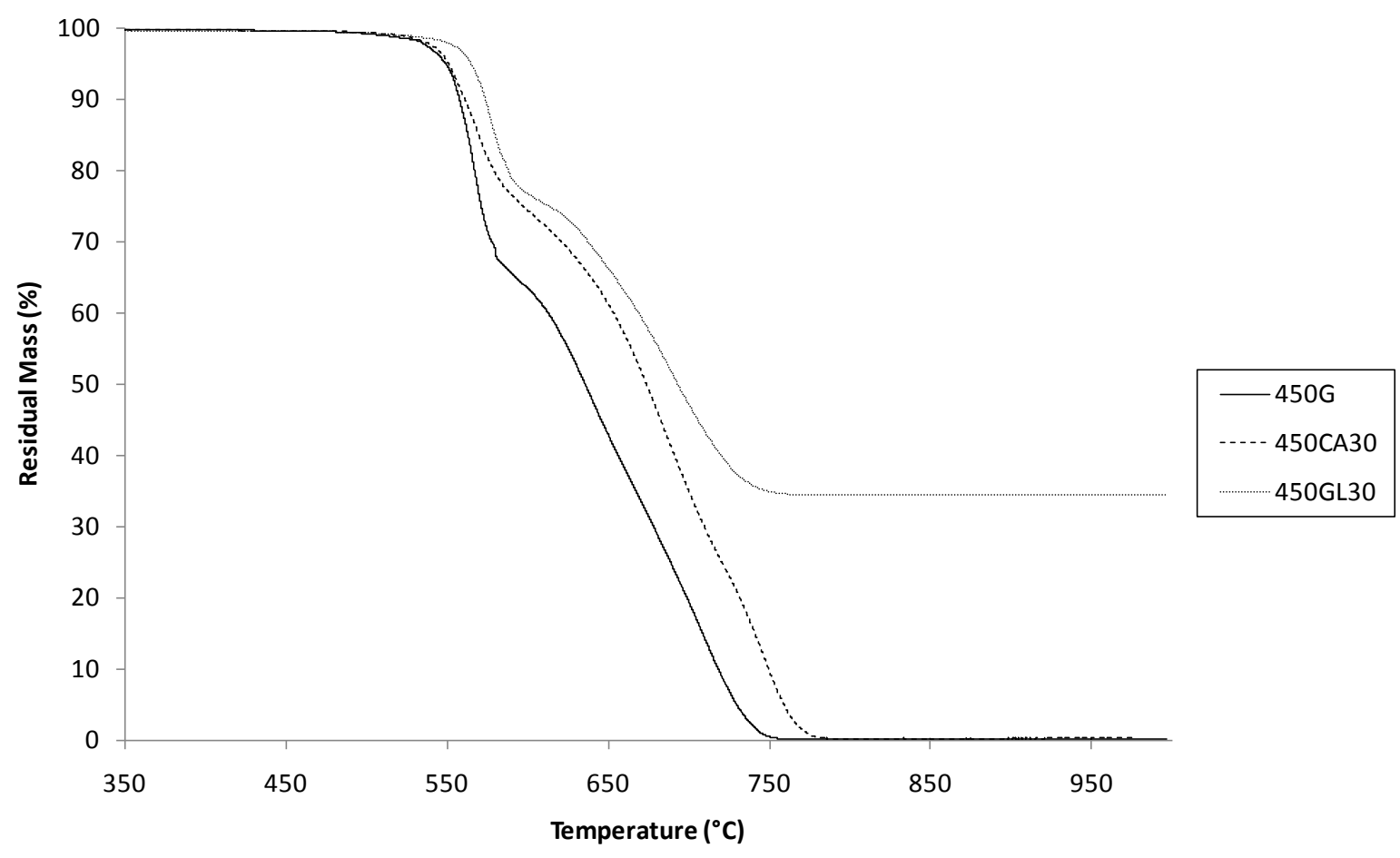

Figure 3. TGA in Air Data for 450G, 450CA30 and 450GL30

Similarly, in an oxidative environment, decomposition of PEEK occurs by a two-step process as shown in Figure 3. The onset of thermal oxidative decomposition for $450 \mathrm{G}$ and $450 \mathrm{CA} 30$ is between $520^{\circ} \mathrm{C}$ and $530^{\circ} \mathrm{C}$. The onset of thermal oxidative decomposition for $450 \mathrm{GL} 30$ is slightly higher at $\sim 560^{\circ} \mathrm{C}$. The difference in stability between the carbon and glass-filled polymers may be due to the oxidation of the carbon fibres resulting in the material losing more weight at an earlier stage. However, the carbon fibre appears slightly more thermally stable than the carbonaceous PEEK residue. $450 \mathrm{G}$ loses $35 \%$ weight in the first stage of thermal oxidative decomposition with $30 \%$ weight loss occurring within a $30^{\circ} \mathrm{C}$ window. This corresponds to the thermal decomposition in an inert atmosphere, indicating that scission of the ether and ketone bonds do not require, or are not enhanced by an oxidative environment. For 450G, the remaining mass is lost in the second decomposition stage where all the carbonaceous material is thermally oxidised by $750^{\circ} \mathrm{C}$. Although $450 \mathrm{CA} 30$ has a similar onset of thermal oxidative decomposition temperature as $450 \mathrm{G}$, it loses mass at a steadier rate. At around $650^{\circ} \mathrm{C}$, there is a $3 \%$ difference in weight loss between $450 \mathrm{CA} 30$ and 
$450 \mathrm{GL} 30$ with a loss of $25 \%$ and $22 \%$ weight loss attributed to the first decomposition stage, respectively. In the second stage of thermal oxidative decomposition, 450CA30 continues to lose $75 \%$ weight at a similar rate to $450 \mathrm{G}$ and the carbonaceous char and carbon fibres are completely oxidised by $775^{\circ} \mathrm{C}$. Weight loss associated with thermal oxidation of the PEEK char continues in the second stage of decomposition with a loss of around $43 \%$ at $800^{\circ} \mathrm{C}$, when the material remains at around $35 \%$ weight up to $1000^{\circ} \mathrm{C}$.

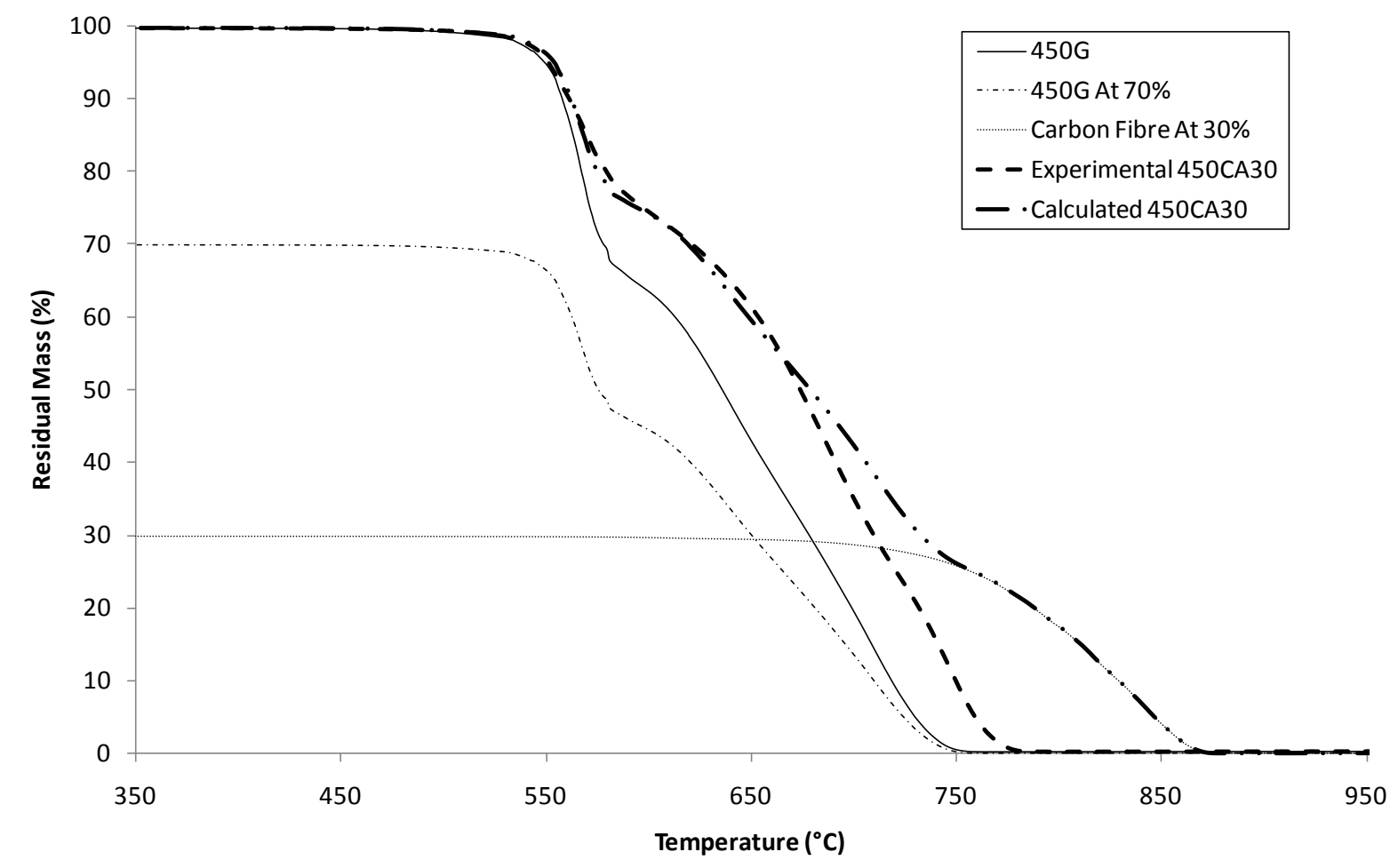

Figure 4. 450G and 450CA30 - Experimental and Calculated TGA in Air

To investigate the affect of carbon fibre on the decomposition of PEEK, a TGA curve has been calculated by proportional addition of the TGAs of the individual components, $450 \mathrm{G}$ and carbon fibre as shown in Figure 4. Interestingly, the experimental and calculated TGA curves for 450CA30 show two slight delays in the actual onset of decomposition to mass losses around $30 \%$ and $50 \%$ followed by significant differences in the second stage of decomposition whereby the calculated 450CA30 is more stable, with total mass loss occurring at $870^{\circ} \mathrm{C}$ compared to $780^{\circ} \mathrm{C}$. The calculated $450 \mathrm{CA} 30$ also shows a distinct third stage of decomposition that is not present in the experimental curve, indicating that this slower oxidation process of carbon fibre is eliminated in the presence of PEEK. This suggests that the PEEK residue enhances the oxidation of carbon fibre. 


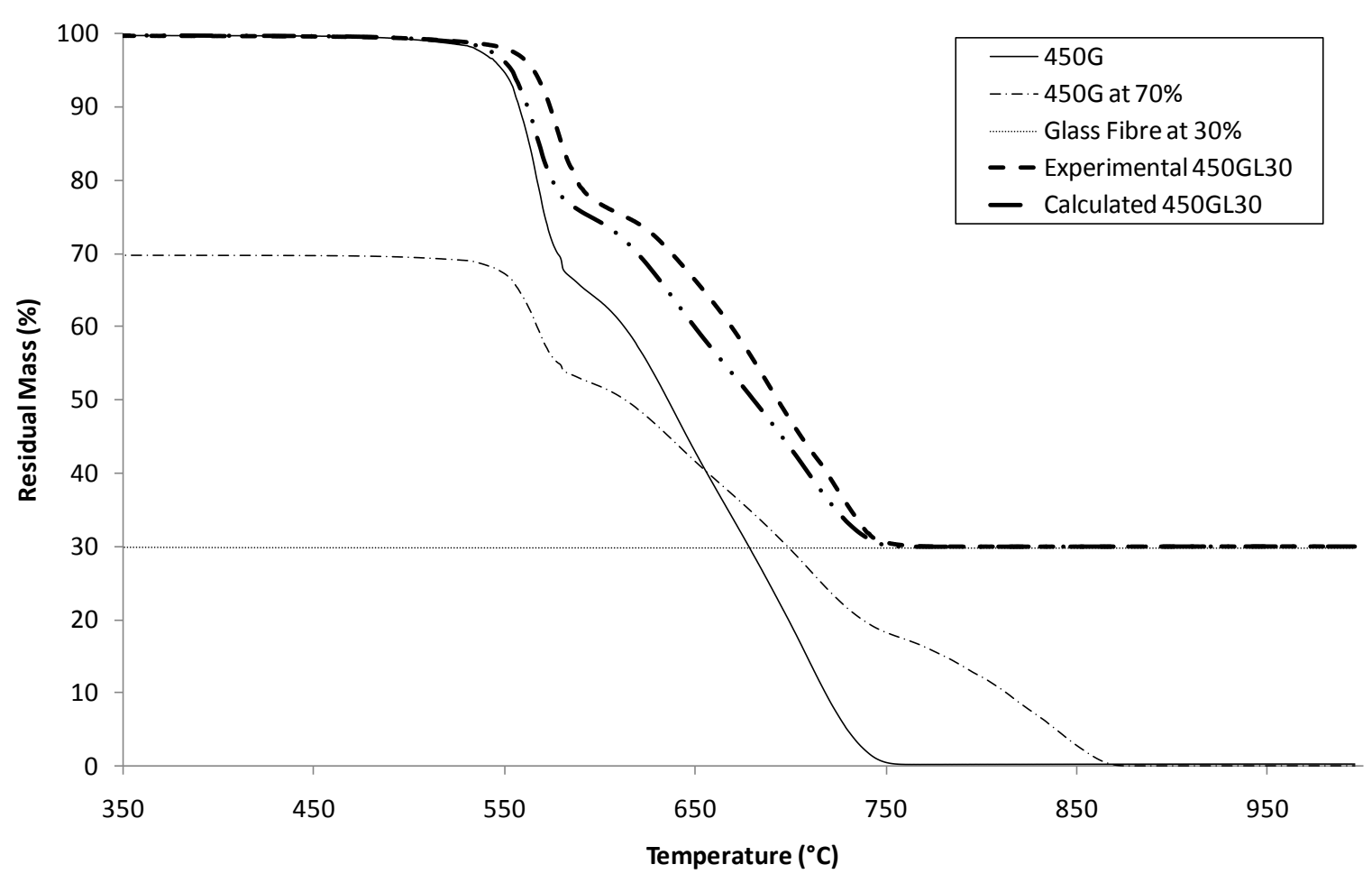

Figure 5. 450G and 450GL30 - Experimental and Calculated TGA in Air

Similarly, a calculated curve has been compared to the actual decomposition of $450 G L 30$ as shown in Figure 5. Here similarities exist between the two curves - to a greater extent than the 450CA30 calculated curve. The presence of glass fibre appears to enhance the onset of decomposition to a greater extent than that seen in the calculated curve. Moreover, no enhancement is evident in the earlier stages of the decomposition of PEEK (equivalent to $30 \%$ and $50 \%$ mass loss) for glass fibrefilled composite. This difference in behaviour between both fibre-filled composites indicates that the modest enhancement in the thermal stability is a chemical effect of carbon fibre rather than the effect of physical blocking by any fibre.

\subsection{Pyrolysis Combustion Flow Calorimeter}

Samples of 450G, 450CA30 and 450GL30 were tested in the PCFC. The results are shown in Figure 6 and a summary of the data is presented in Table 1 . The unfilled polymer begins releasing heat prior to the filled polymers; this is expected as $450 \mathrm{G}$ thermally decomposes earlier than the filled polymers as seen in the anaerobic TGA experiments. The average peak heat release rate of the unfilled samples is $302 \mathrm{~W} \mathrm{~g}^{-1}$ and therefore higher than the filled samples. Again there are differences between the filled materials. 450GL30 gives a higher average peak heat release rate (232 $\left.\mathrm{W} \mathrm{g}^{-1}\right)$ than 450CA30 $\left(195 \mathrm{~W} \mathrm{~g}^{-1}\right)$. However, both reduce the peak heat release rate when compared to the unfilled material with a $35 \%$ reduction for 450 CA30 and a $23 \%$ reduction for $450 \mathrm{GL} 30$.

Interestingly, the presence of $30 \%$ filler does not reduce the peak heat release rate uniformly. In the glass fibre-filled composite a more rapid pyrolysis rate, and hence the release of flammable material occurs compared to the carbon-fibre composite. The temperature at incipient heat release rate 
(onset temperature) corresponds to the transient ignition temperature (flashpoint) of PEEK, while the temperature at peak heat release rate in the PCFC corresponds to the sustained ignition (steady burning) temperature [35]. The average peak heat release rate temperature for $450 \mathrm{G}$ is $618^{\circ} \mathrm{C}$, for $450 \mathrm{CA} 30$ is $621^{\circ} \mathrm{C}$ and for $450 \mathrm{GL} 30$ is $623^{\circ} \mathrm{C}$. It has been argued that around $10 \%$ mass loss in the TGA in air corresponds to the piloted ignition temperature [29]. In an inert atmosphere in the TGA, $450 \mathrm{G}$ reaches $10 \%$ mass loss at $576^{\circ} \mathrm{C}, 450 \mathrm{CA} 30$ at $583^{\circ} \mathrm{C}$ and $450 \mathrm{GL} 30$ at $586^{\circ} \mathrm{C}$. These temperatures are similar to the onset heat release rate temperatures determined from the PCFC data. The differences are due to the higher heating rate $\left(60^{\circ} \mathrm{C} \mathrm{min}^{-1}\right)$ in the PCFC. The anaerobic pyrolysis residues/char yields $\left(\mathrm{Y}_{c}\right)$ in the TGA and PCFC show good agreement. The sample heat release (HR) of the $450 \mathrm{G}$ in the PCFC is reduced by the inert fraction of glass/carbon fibre (30\%) for the $450 \mathrm{GL30}$ and 450CA30 composites. However, the average heat of combustion of the pyrolysis gases, $\mathrm{H}_{\mathrm{c}}=$ $\mathrm{HR} /\left(1-Y_{c}\right) \approx 22 \mathrm{~kJ} / \mathrm{g}$-gas is independent of the presence or absence of reinforcing fibre, as would be expected for inert filler.

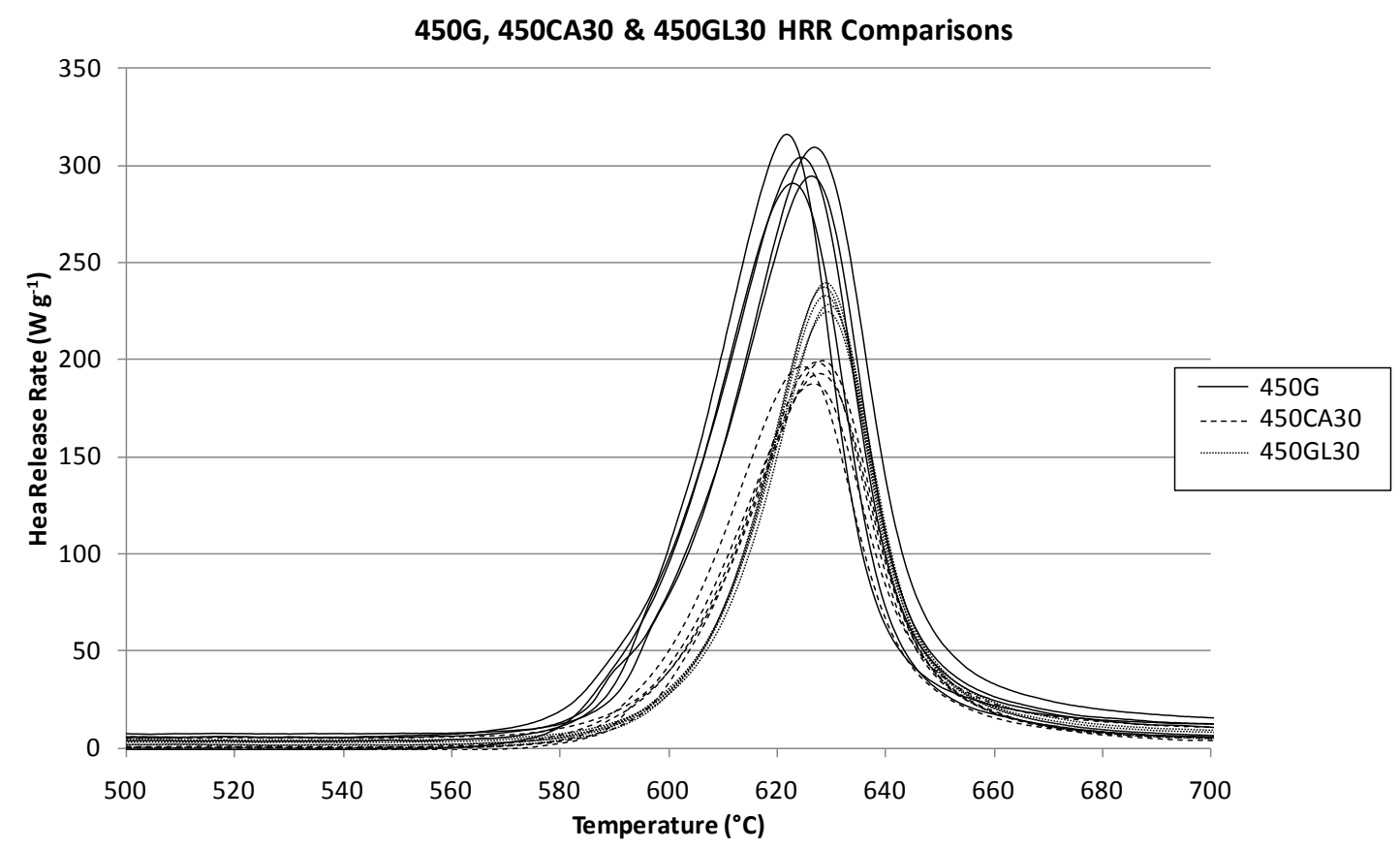

Figure 6. PCFC Heat Release Curves for PEEK 450G, 450CA30 and 450GL30

\begin{tabular}{|c|c|c|c|c|c|c|}
\cline { 2 - 7 } \multicolumn{1}{c|}{} & $\begin{array}{c}\text { Onset Heat Release } \\
\text { Rate Temperature }\end{array}$ & \begin{tabular}{c} 
Peak Heat Release \\
Rate Temperature \\
\cline { 2 - 7 }
\end{tabular} & $\begin{array}{c}\text { Peak Heat } \\
\text { Release Rate }\end{array}$ & Char & $\begin{array}{c}\text { Heat } \\
\text { Release }\end{array}$ & $\begin{array}{c}\text { Heat of } \\
\text { Combustion } \\
\text { Gases }\left(\mathrm{H}_{\mathrm{c}}\right)\end{array}$ \\
\hline 450G & $594 \pm 1.8$ & $611.2 \pm 2.2$ & $302.8 \pm 10.3$ & $51.6 \pm 2.6$ & $10.7 \pm 0.3$ & 22.1 \\
\hline 450CA30 & $596.4 \pm 0.9$ & $613.6 \pm 1.5$ & $194.9 \pm 4.8$ & $68.5 \pm 3.8$ & $7.0 \pm 0.2$ & 22.2 \\
\hline 450GL30 & $605.6 \pm 0.5$ & $615.7 \pm 0.3$ & $232.5 \pm 6.1$ & $65.9 \pm 1.5$ & $7.2 \pm 0.1$ & 21.1 \\
\hline
\end{tabular}

Table 1. Summary of PCFC Data for PEEK and Composites 


\subsection{Limiting Oxygen Index}

Samples of 450G, 450CA30 and 450GL30 were tested in the LOI and results are shown in Table 2. $450 \mathrm{G}$ exhibited a lower LOI value than both filled materials as expected from the TGA and PCFC data whereby filled composites have a greater thermal stability than unfilled samples. Again there were differences between the filled materials - 450CA30 had a higher LOI than 450GL30 albeit by $0.8 \%$. There were also differences in the ways the materials behaved during the tests. 450CA30 samples would curl in on themselves - thus enclosing the flame and causing the sample to extinguish (see Figure 7). Similarly, 450GL30 samples twist round themselves and enclose the flame (see Figure 8) although this occurred to a lesser extent than with the carbon fibre-filled samples. A possible reason for this effect is the residual stress present from injection moulding the polymer samples and exists to a greater extent in the fibre-filled samples. These differences in physical behaviour may account for the differences in the LOI values of the fibre-filled composites; the 'curling' seems to be quite effective at enclosing a flame and promoting self extinguishing behaviour, however should be seen as an artefact of the LOI test in terms of quantifying flammability.

\begin{tabular}{|c|c|c|}
\hline Material & LOI & Comments \\
\hline PEEK 450G & $37.3 \%$ & $\mathrm{n} / \mathrm{a}$ \\
\hline PEEK 450CA30 & $45.5 \%$ & Samples curl in on themselves \\
\hline PEEK 450GL30 & $44.7 \%$ & Samples twist around themselves \\
\hline
\end{tabular}

Table 2. LOI Data for 450G, 450CA30 and 450GL30

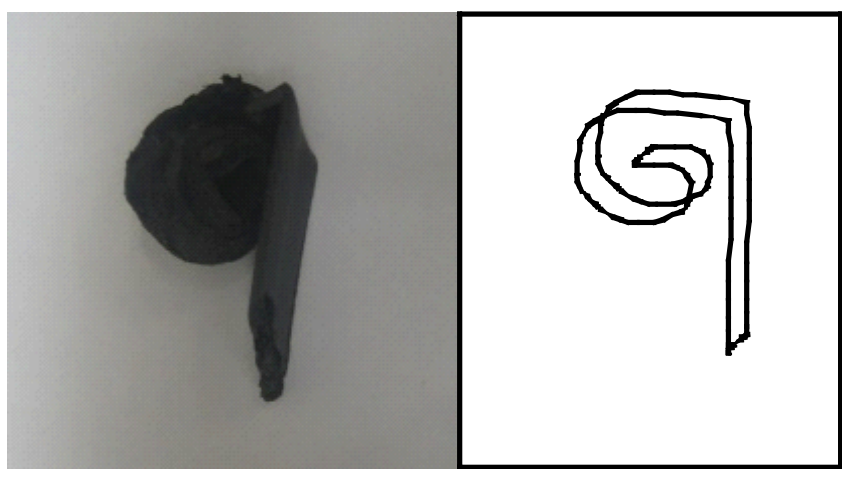

Figure 7. 450CA30 LOI Sample 'Curling' 


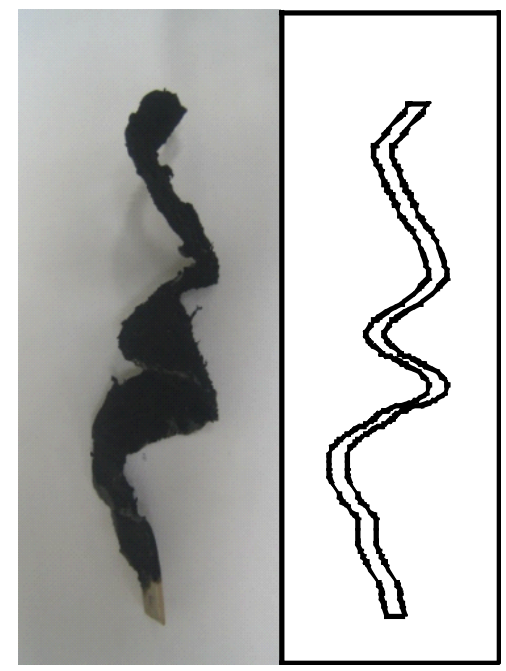

Figure 8. 450GL30 LOI Sample 'Twisting'

\subsection{Underwriters Laboratory Vertical Test for Flammability of Plastics (UL94-V)}

All materials tested were classified as achieving the optimum UL-94 rating (V-0). Differences exist in the burn times $t_{1}$ and $t_{2}$ of the filled and unfilled polymers as shown in Table 3. $t_{1}$ refers to the time a flame is sustained after the primary 10 second flame application and $t_{2}$ refers to the time a flame is sustained after the secondary 10 second flame application. For $450 G, t_{1}$ is on average greater than $t_{2}$ : for both $450 \mathrm{CA} 30$ and $450 \mathrm{GL} 30$, the opposite is true. Once ignited, the unfilled polymer char is less easy to reignite while the filled polymer char is easier to reignite. There also appears to be a greater burn length and a shorter total burn time (the sum of $t_{1}$ and $t_{2}$ ) for the filled samples- although there is uncertainty due to the scatter present in the data. It is interesting that although there are clear differences between the filled and unfilled polymer in terms of burning behaviour, these differences are not evident within the V-0 UL-94 test criterion. Correlations have been found between cone calorimeter peak heat release rate data and UL-94 V-ratings although the closest correlations were observed at low heat fluxes $\left(30 \mathrm{~kW} \mathrm{~m}^{-2}\right)$, close to the ignitability limits for many materials [36]. The critical heat flux (CHF) for ignition of PEEK is calculated as the sum of the radiative and convective heat losses at incipient ignition:

$$
\mathrm{CHF}=\alpha \sigma\left(T_{i g n}^{4}-T_{0}^{4}\right)+h\left(T_{i g n}-T_{0}\right) \approx 24 \mathrm{~kW} \mathrm{~m}{ }^{-2}
$$

In Equation 1, the surface absorptivity is $\alpha=0.8$, the ignition temperature is assumed to be equal to the onset thermal (oxidative) decomposition temperature $T_{\text {ign }}=808 \mathrm{~K}\left(535^{\circ} \mathrm{C}\right)$, the ambient temperature is $T_{0}=298 \mathrm{~K}\left(25^{\circ} \mathrm{C}\right)$, the convective heat transfer coefficient in the cone calorimeter is $h$ $=10 \mathrm{~W} / \mathrm{m}^{2}-\mathrm{K}$, and $\sigma$ is the Stefan-Boltzmann constant $\left(5.67 \times 10^{-8} \mathrm{~W} \mathrm{~m}^{-2} \mathrm{~K}^{4}\right)$. The calculated CHF is in reasonable agreement with experimental values between 30 and $40 \mathrm{~kW} \mathrm{~m}^{-2}$ [37]

\begin{tabular}{|c|c|c|c|c|}
\cline { 2 - 5 } \multicolumn{1}{c|}{} & $t_{1}$ & $t_{2}$ & Total Time & Burn Length \\
\hline Sample & $(\mathrm{s})$ & $(\mathrm{s})$ & $(\mathrm{s})$ & $(\mathrm{mm})$ \\
\hline 450G & $3.7 \pm 1.0$ & $2.7 \pm 1.1$ & $6.5 \pm 1.1$ & $30.9 \pm 7.9$ \\
\hline 450CA30 & $1.9 \pm 1.3$ & $4.1 \pm 1.5$ & $6.0 \pm 1.9$ & $34.0 \pm 17.5$ \\
\hline 450GL30 & $2.2 \pm 0.8$ & $3.5 \pm 0.9$ & $5.7 \pm 1.5$ & $39.4 \pm 26.1$ \\
\hline
\end{tabular}

Table 3. UL-94 Average Data for 450G, 450CA30 and 450GL30 


\subsection{Fire (Cone) Calorimetry}

Samples of PEEK 450G, 450CA30 and 450GL30 were tested in the cone calorimeter in triplicate at 50 $\mathrm{kW} \mathrm{^{-2 }}$. In these and other studies, we have observed inconsistencies in the burning behaviour of PEEK compared to other materials. The individual heat release rates are shown in Figure 9, Figure 10 and Figure 11 respectively, together with their average data summarised in Table 4. For the unfilled polymer (450G), all three samples ignited within a 15 second window - the average time to ignition was 110 seconds. In terms of burning behaviour, all three samples ignited, reached a shoulder at around 140 seconds and $200 \mathrm{kWm}^{-2}$, and then continued to burn to reach an average peak heat release rate of $415 \mathrm{~kW} \mathrm{~m}^{-2}$. An average char yield of $50.6 \%$ was obtained with an average of $36.2 \mathrm{MJ}$ $\mathrm{m}^{-2}$ heat released in total. After the flame extinguishes, the heat release rate does not return to zero as the char continues to oxidise (smoulder) without flaming as evident in all three heat release curves. The effective heat of flaming combustion per unit mass of volatiles up to the point of flame extinction is reported as EHOC in Table 4. Dividing the effective heat of combustion of the volatiles $\mathrm{EHOC}$ by the heat of complete combustion of the volatiles $\mathrm{H}_{c}$ from Table 1 gives the flaming combustion efficiency in the cone calorimeter, $\chi=E H O C / \mathrm{H}_{c}$ listed in Table 4. It is seen that the combustion efficiency is approximately $90 \%$ for PEEK burning in the well-ventilated cone calorimeter, independent of the presence or absence of reinforcing fibre as would be expected for gas phase combustion chemistry.

For the carbon fibre-filled samples (450CA30), the average time to ignition was 156 seconds and samples burned with an average peak heat release rate of $147 \mathrm{~kW} \mathrm{~m}^{-2}$. An average char yield of $66.4 \%$ was obtained with an average of $26.9 \mathrm{MJ} \mathrm{m}^{-2}$ of total heat released. Similarly to the $450 \mathrm{G}$ samples, the heat release rate does not return to zero.

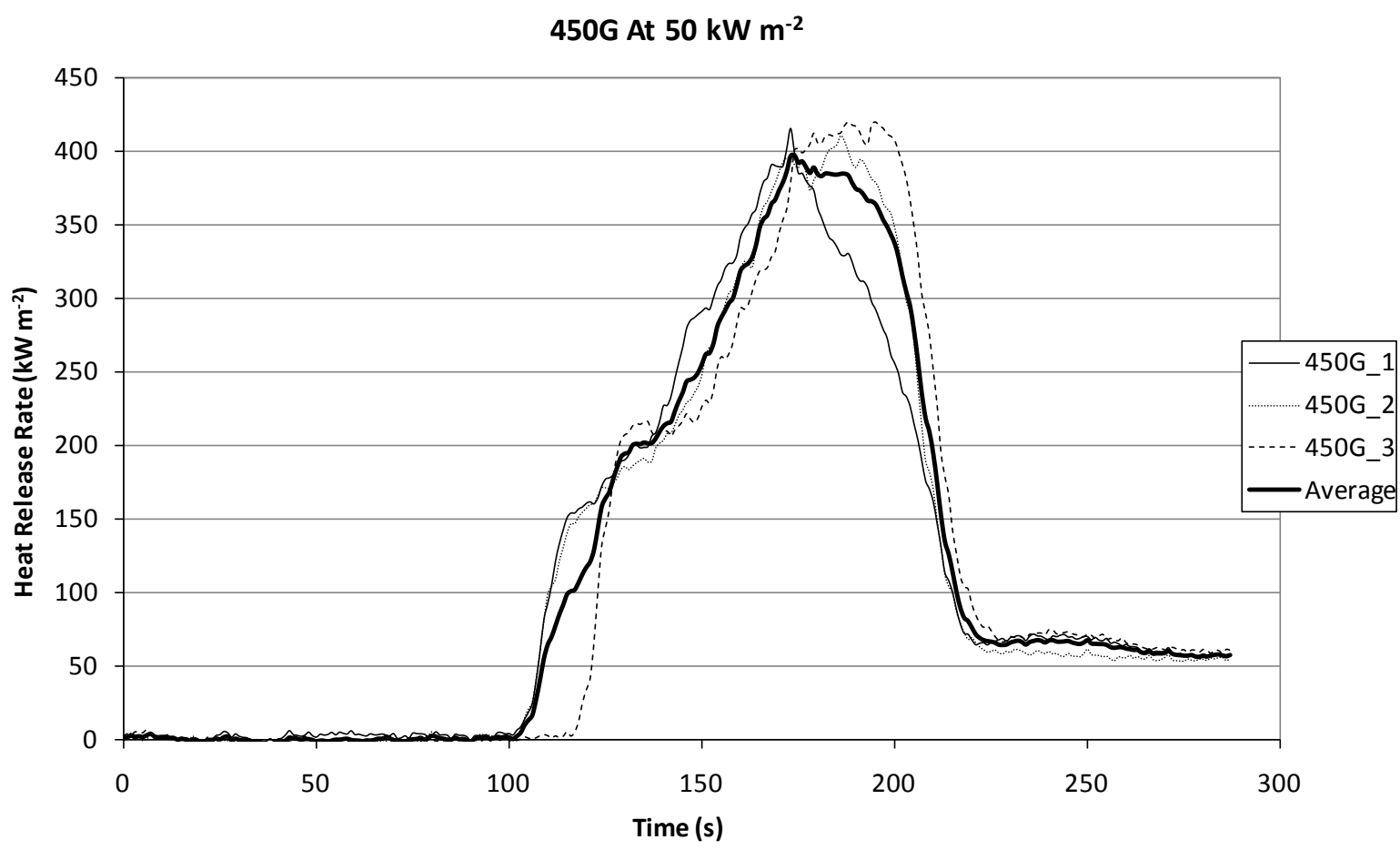

Figure 9. Cone Calorimeter Data for HRR of PEEK 450G. Triplicates and Average 


\begin{tabular}{|c|c|c|c|c|c|c|c|}
\cline { 2 - 7 } \multicolumn{1}{c|}{} & $\begin{array}{c}\text { Time to } \\
\text { Ignition }\end{array}$ & PHRR & tPHRR & Char Yield & EHOC & THR & $\chi$ \\
\cline { 2 - 8 } & $(\mathrm{s})$ & $\left(\mathrm{kW} \mathrm{m}^{-2}\right)$ & $(\mathrm{s})$ & $(\%)$ & $(\mathrm{J} / \mathrm{kg})$ & $\left(\mathrm{kW} \mathrm{m}^{-2}\right)$ & \\
\hline $450 \mathrm{G}$ & $110 \pm 8$ & $415.2 \pm 4.9$ & $182 \pm 8$ & $50.6 \pm 1.6$ & $1.999 \times 10^{7}$ & $36.2 \pm 1.1$ & $90 \%$ \\
\hline 450CA30 & $156 \pm 13$ & $146.7 \pm 5.8$ & $279 \pm 20$ & $66.4 \pm 2.9$ & $1.022 \times 10^{7}$ & $26.9 \pm 2.6$ & $87 \%$ \\
\hline 450GL30 & $115 \pm 15$ & $120.5 \pm 13$ & $278 \pm 5$ & $71.8 \pm 0.3$ & $7.552 \times 10^{6}$ & $23.3 \pm 1.9$ & $88 \%$ \\
\hline
\end{tabular}

Table 4. PEEK and Composites at $50 \mathrm{~kW} \mathrm{~m}^{-2}$ - Summary: Time to Ignition, Peak Heat Release Rate (PHRR), Time to Peak Heat Release Rate (tPHRR), Char Yield, Effective Heat of Combustion (EHOC), Total Heat Released (THR) and Flaming Combustion Efficiency $(\chi)$

For the glass fibre-filled samples (450GL30) the average time to ignition was 115 seconds and samples burned with an average peak heat release rate of $121 \mathrm{~kW} \mathrm{~m}^{-2}$. An average char yield of $71.8 \%$ was obtained with an average of $23.3 \mathrm{MJ} \mathrm{m}^{-2}$ total heat released. Again, like the $450 \mathrm{G}$ and 450 CA30 samples, the $450 \mathrm{GL} 30$ heat release curves do not return to zero.

\section{$450 \mathrm{CA} 30$ at $50 \mathrm{~kW} \mathrm{~m}^{-2}$}

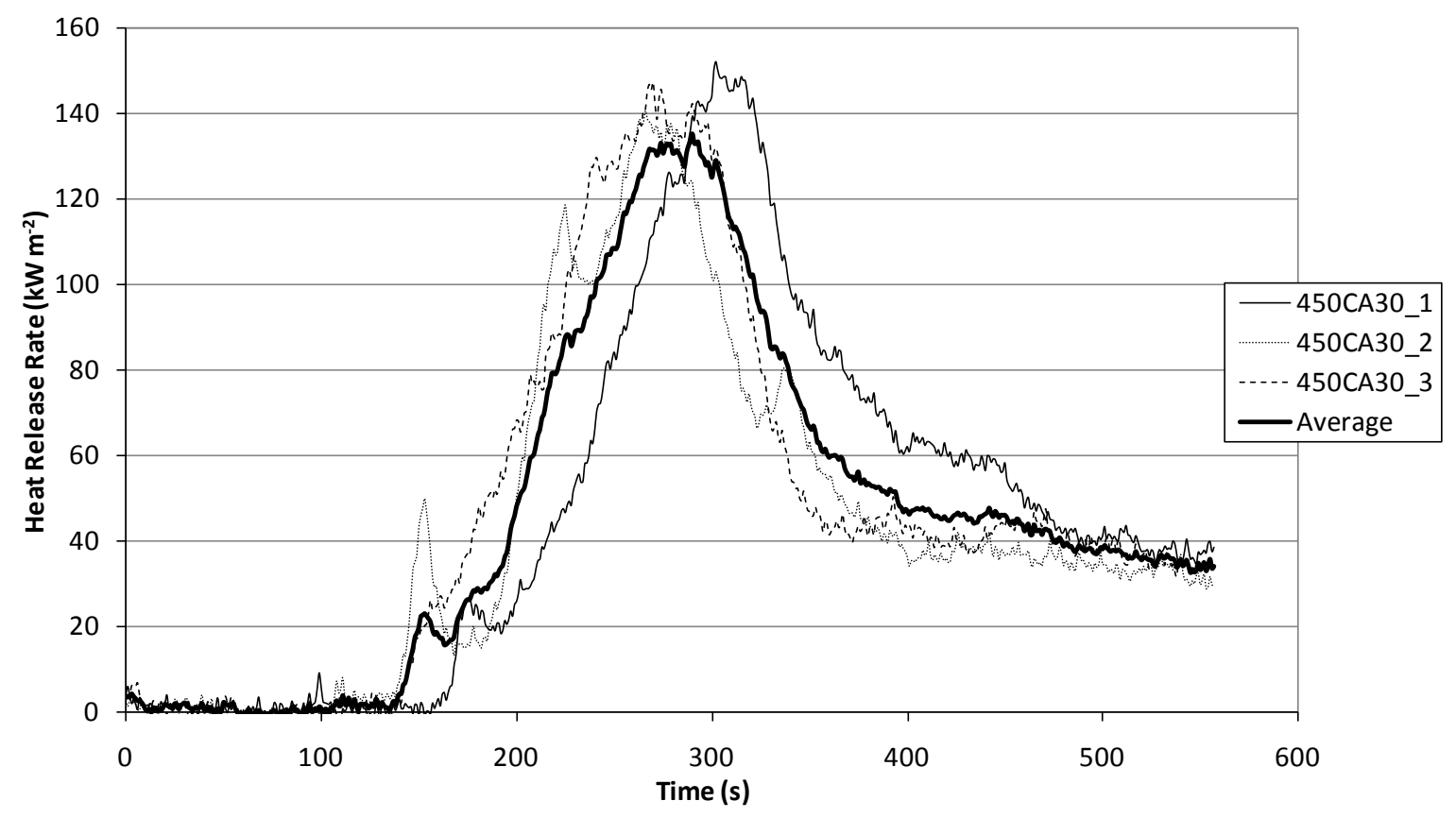

Figure 10. Cone Calorimeter Data for HRR of PEEK 450CA30. Triplicates and Average 


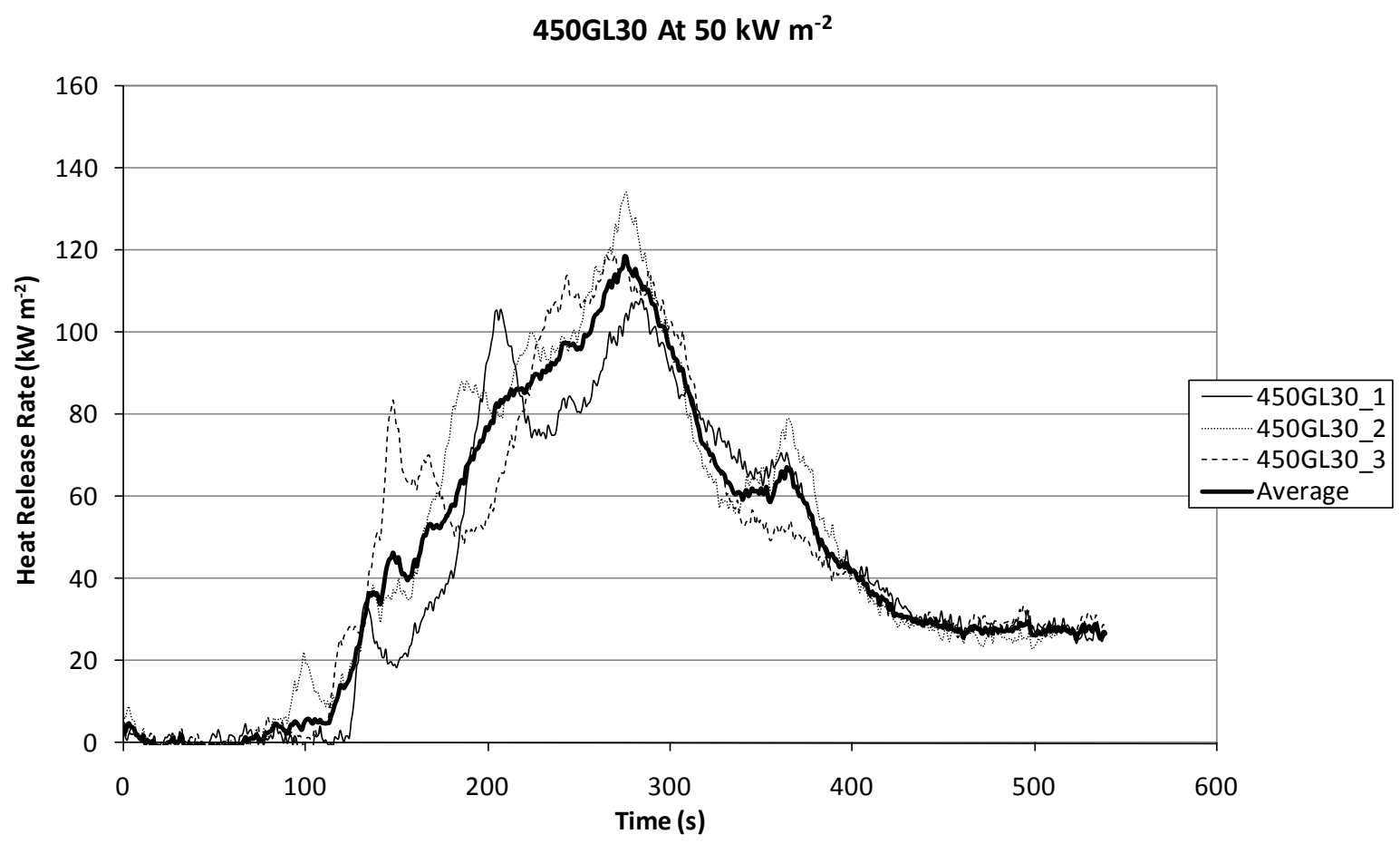

Figure 11. Cone Calorimeter Data for HRR of PEEK 450GL30. Triplicates and Average

Ignition Behaviour of 450G, 450CA30 and 450GL30

Piloted ignition is sustained when the heat released from the combustion of volatilised fuel is sufficient to vaporise its replacement from the condensed phase. For the horizontal sample configuration of the cone calorimeter, only a small portion of the radiant heat will be transmitted back to the condensed phase fuel and therefore, only a portion of this heat will result in fuel volatilisation. For thermally thick solids (typically thicknesses above $1.5 \mathrm{~mm}$ [38]) the thermal inertia, $k \rho c$, which is the product of thermal conductivity $(k)$, density $(\rho)$, and specific heat $(c)$, governs the material's ignition and flame spread properties for a given set of conditions. It is the rate at which the surface reaches the thermal (oxidative) decomposition temperature and generates gaseous fuel, that controls the time to ignition [37] - [39]. The time to ignition $\left(t_{i g}\right)$ of a thermally thick solid exposed to a constant net heat flux, $Q_{R}=Q_{e x t}-\mathrm{CHF}$ is obtained from unsteady heat conduction as:

$$
t_{i g}=\frac{\pi}{4} k \rho c \frac{\left(T_{i g}-T_{0}\right)^{2}}{\dot{Q}_{\dot{R}}{ }^{2}}
$$

The material properties $k \rho c$ are presumed to be known, at least under ambient conditions; and an estimate for the temperature at ignition is the onset thermal oxidation decomposition temperature in the TGA, $T_{i g n}=808 \mathrm{~K}$. The samples tested in the cone calorimeter for this study were $2.5 \mathrm{~mm}$ in thickness and as a result, the thermally thin scenario may be more appropriate. The time to ignition of a thermally thin solid exposed to a constant net heat flux has been expressed through the following: 


$$
t_{i g}=\rho c \tau \frac{\left(T_{i g}-T_{0}\right)}{\dot{Q}_{\dot{R}}}
$$

Where $\tau=0.0025 \mathrm{~m}$ is the thickness of the cone calorimeter samples. The values for $k, \rho$ and $c$ listed in Table 5 (obtained from Victrex plc - Technical Data Sheets) were used to calculate the time to ignition for PEEK and its composites using $T_{\text {ign }}=808 \mathrm{~K}$ and $Q_{R}=Q_{\text {ext }}-C H F=50 \mathrm{~kW} / \mathrm{m}^{2}-24 \mathrm{~kW} / \mathrm{m}^{2}=$ $26 \mathrm{~kW} / \mathrm{m}^{2}$ for both the thermally-thin and thermally-thick cases. The results of these calculations are shown in Table 5.

Where $\tau=0.0025 \mathrm{~m}$ is the thickness of the cone calorimeter samples. The values for $k, \rho$ and $c$ listed in Table 5 (obtained from Victrex plc - Technical Data Sheets) were used to calculate the time to ignition for PEEK and its composites using $T_{\text {ign }}=808 \mathrm{~K}$ and $\mathrm{Q}_{\mathrm{R}}=\mathrm{Q}_{\text {ext }}-\mathrm{CHF}=50 \mathrm{~kW} / \mathrm{m}^{2}-24 \mathrm{~kW} / \mathrm{m}^{2}=$ $26 \mathrm{~kW} / \mathrm{m}^{2}$ for both the thermally-thin and thermally-thick cases. The results of these calculations are shown in Table 5.

\begin{tabular}{|c|c|c|c|c|c|c|c|}
\hline & \multicolumn{4}{|c|}{ Input Data } & \multirow[b]{2}{*}{$\begin{array}{c}\text { Predicted } \\
\text { Thermally } \\
\text { Thin } \\
t_{i g}\end{array}$} & \multirow[b]{2}{*}{$\begin{array}{c}\text { Predicted } \\
\text { Thermally } \\
\text { Thick } \\
t_{i g}\end{array}$} & \multirow[b]{2}{*}{$\begin{array}{c}\text { Actual Cone } \\
t_{i g}\end{array}$} \\
\hline & $k$ & $\rho$ & c & $T_{i g}$ & & & \\
\hline & 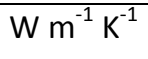 & $\mathrm{Kg} \mathrm{m}^{-3}$ & $\mathrm{~J} \mathrm{Kg}^{-1} \mathrm{~K}^{-1}$ & K & $\mathrm{s}$ & $\mathrm{s}$ & $\mathrm{s}$ \\
\hline $450 \mathrm{G}$ & 0.25 & 1300 & 2160 & 808 & 138 & 212 & $110 \pm 8$ \\
\hline 450СA30 & 0.92 & 1410 & 1850 & 808 & 128 & 725 & $156 \pm 13$ \\
\hline 450GL30 & 0.43 & 1510 & 1710 & 808 & 127 & 336 & $115 \pm 15$ \\
\hline
\end{tabular}

Table 5. Time to Ignition Parameters, Prediction and Comparison with Actual Data

The time for the surface temperature to reach the ignition temperature following an instantaneously applied and constant net heat flux (time to ignition) calculated for the thermally-thin case correlates more closely to the experimental values for PEEK and its composites than does the thermally-thick case. However, calculations of this nature rely on the concept of an ignition temperature, which is only one of several criteria proposed for ignition of combustible solids [35]. The calculated time to ignition for the fibre-filled composites is slightly lower, possibly due to a lower specific heat. 


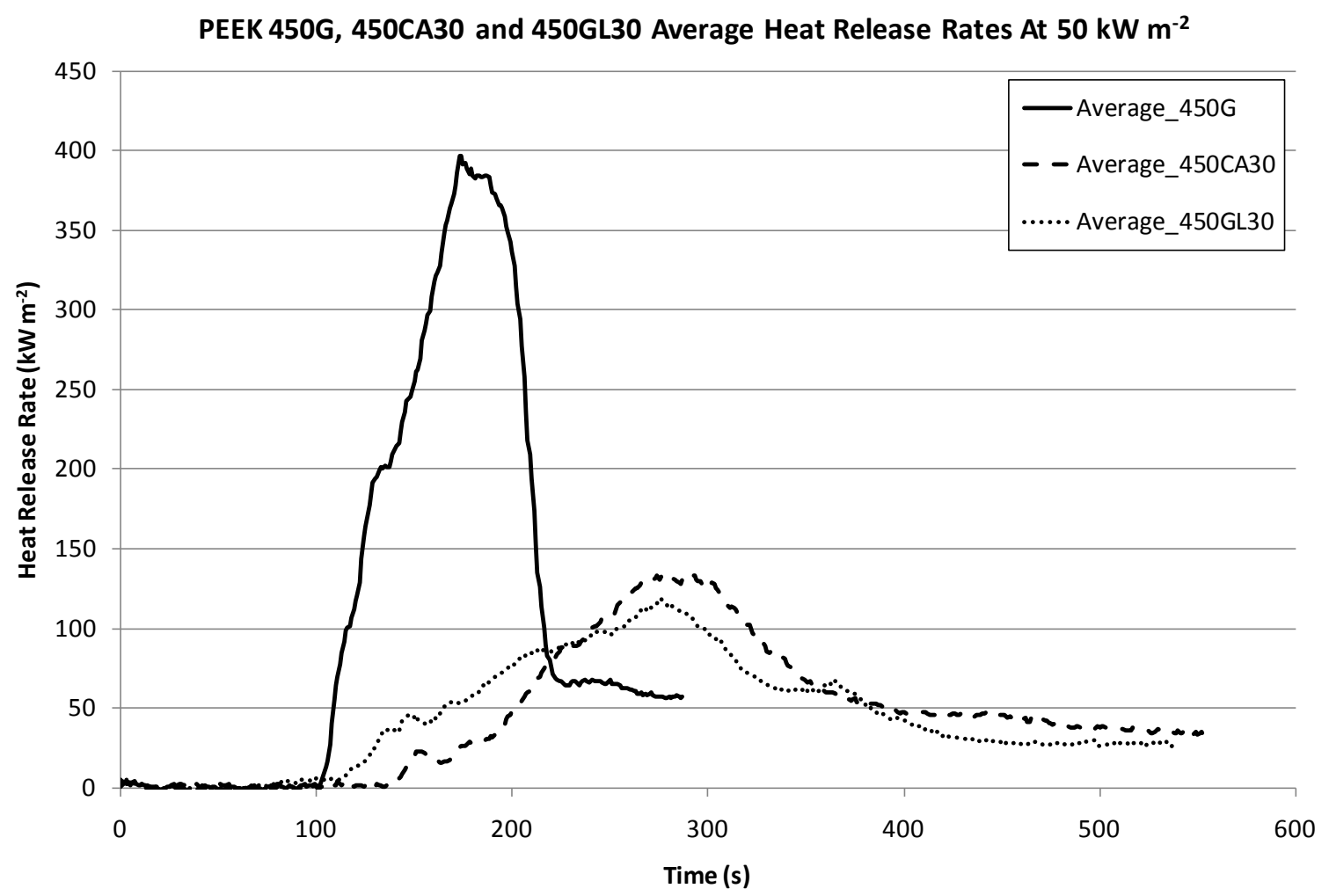

Figure 12. Cone Calorimeter Data for Average HRR of PEEK 450G, 450CA30 and 450GL30

The average heat release rate curves of PEEK and its carbon and glass fibre composites are shown in Figure 12. The shapes of cone calorimeter heat release rate curves have been discussed previously [40] [41]. The virgin polymer (450G) initially exhibits 'intermediate thick non-charring' behaviour showing a short period of steady heat release rate marked by a shoulder within the curve. As the remaining material becomes thinner, all of the applied heat flux is concentrated on a small amount of fuel, which as a result, burns quicker. Both the filled samples behave in a similar manner but may be characterised as 'thick charring' depicted by an initial increase in heat release rate until an effective char layer has been formed. As this layer continues to thicken, the heat release rate decreases until the polymer extinguishes.

The unfilled polymer exhibits a much higher peak of heat release rate than the filled polymers. A similar but smaller effect is seen in the PCFC data. There are also differences between the carbon and glass fibre-filled composites in terms of burning behaviour. The presence of fillers reduces the peak heat release rate by $64 \%$ for 450 CA30 and $71 \%$ for 450 GL30 in the cone calorimeter: 450 CA30 exhibits a higher peak of heat release, approximately $25 \mathrm{~kW} \mathrm{~m}^{-2}$ higher than $450 \mathrm{GL} 30$. The reduction in heat release rate due to the presence of filler is observed to a lesser extent in the PCFC.

Additionally, in the PCFC, 450CA30 shows a greater reduction in heat release rate than 450GL30, the opposite of that observed in the cone calorimeter. These differences could be accounted for by the differences in the nature of each experiment. In the PCFC, and similarly in the TGA samples are heated from numerous directions from the furnace. In the cone calorimeter, samples are exposed to a radiant heat source and therefore heating of the polymer occurs initially through radiative heat transfer with the presence of a (black) carbon fibre having a greater ability to absorb radiation close to the surface.

In the cone calorimeter, the total heat released is lower for the filled materials with a reduction of $26 \%$ for 450 CA30 and 35\% for 450GL30. In the PCFC data, both fillers reduce the total heat released 
by $30 \%$ when compared to $450 \mathrm{G}$, which may be expected with the absence of $30 \%$ polymer. In the cone calorimeter, the combination of oxygen and radiant heat causes some oxidation of the carbon fibre. In the PCFC, under nitrogen, the carbon fibre will remain in the condensed phase.

\section{Comparison of Charring Behaviour}

From TGA data in nitrogen, PEEK has a char yield of 50\% for the virgin polymer and $\sim 70 \%$ for the filled composites. It is worth noting that subsequent to ignition, all samples show a significant degree of intumescence (see Figure 13 for 450G). As seen in Figure 14 the intumescing structure formed from the radiant heating of $450 \mathrm{GL} 30$ has greater structural integrity than the structure formed by 450CA30 (Figure 15) presumably due to fusion of the glass fibres. The very large differences in the char shape after intumescence will affect the heat release rate. As the unfilled char swells, it will become very close to the cone heater, and the applied heat flux will increase. This will have two consequences, increasing char oxidation near the heater, while protecting any unburned polymer near the base of the swollen mass. For the filled samples, the intumescence is held back by the reinforcing fibres and this effect is much less apparent. It could be argued that the heat flux on swelling was an artefact of behaviour in the cone calorimeter that would not be observed in a real fire. In addition, the one-dimensional burning of a larger bulk of material (a 2.5 $\mathrm{mm}$ thick cone calorimeter sample) allows the fibres to reinforce the char structure, acting as a physical and radiation barrier. In the PCFC and TGA, where no temperature gradient exists within the sample, this protective effect is not observed, hence the higher char yields in the cone calorimeter. The char yields obtained from TGA, PCFC and cone calorimetry are shown in Table 6 . Similar values are attained by the TGA and PCFC, with differences attributed to the heating rate used.

\begin{tabular}{|r|c|c|c|}
\cline { 2 - 4 } \multicolumn{1}{c|}{} & \multicolumn{3}{c|}{ Char Yield (\%) } \\
\cline { 2 - 4 } & $\begin{array}{c}\text { TGA N }_{2} \\
\left.\text { (at } 900^{\circ} \mathrm{C}\right)\end{array}$ & PCFC & Cone \\
\hline $450 \mathrm{G}$ & 49 & $51.6 \pm 2.6$ & $50.6 \pm 1.6$ \\
\hline $450 \mathrm{CA30}$ & 65 & $68.5 \pm 3.8$ & $66.4 \pm 2.9$ \\
\hline $450 \mathrm{GL30}$ & 68 & $65.9 \pm 1.5$ & $71.8 \pm 1.9$ \\
\hline
\end{tabular}

Table 6. Char Yield Comparison of 450G, 450CA30 and 450GL30 


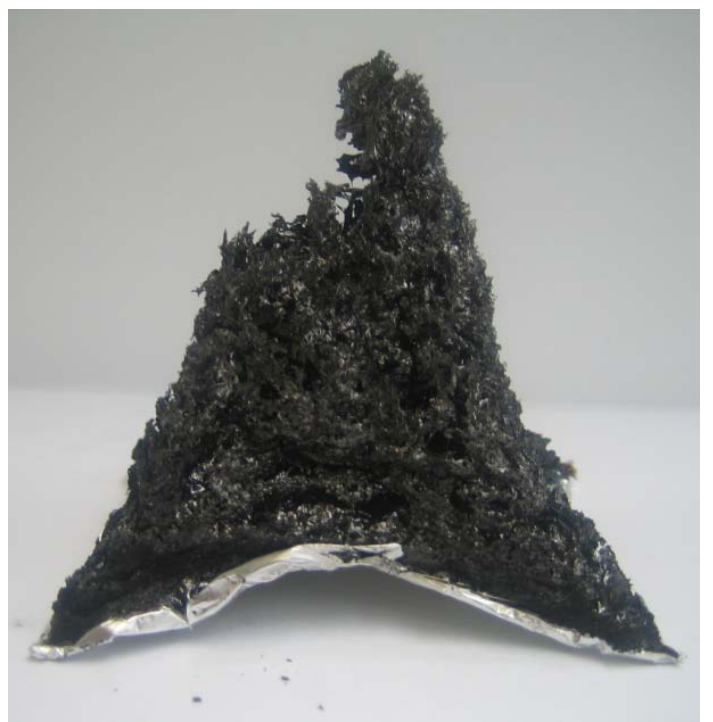

Figure 13. 450G Cone Calorimeter Sample Intumescence

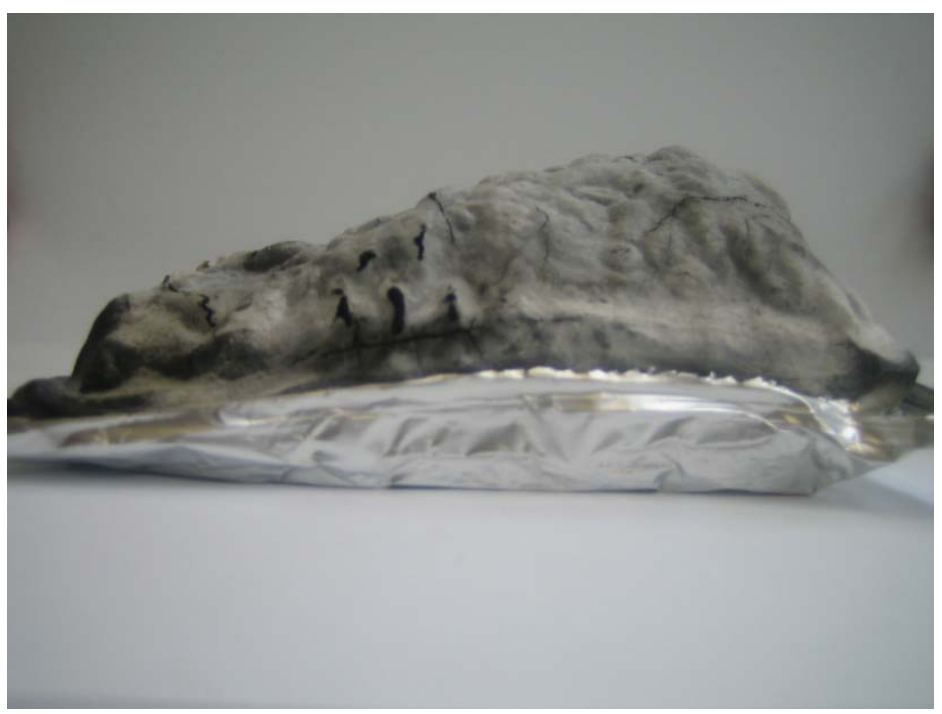

Figure 14. 450GL30 Cone Calorimeter Sample Intumescence 


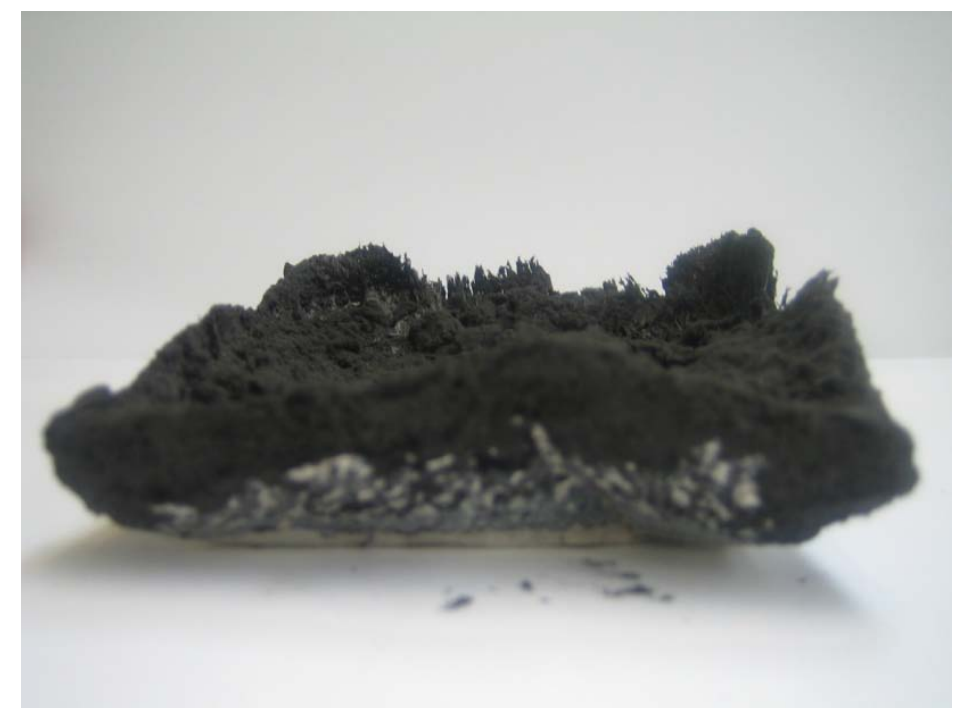

Figure 15. 450CA30 Cone Calorimeter Sample Intumescence

\section{Conclusions}

PEEK is very heat resistant, with negligible thermal decomposition below $550^{\circ} \mathrm{C}$. PEEK thermal decomposition occurs via a two-step process. In the virgin polymer, $30 \%$ of the PEEK is decomposed to gaseous fuel within a $30^{\circ} \mathrm{C}$ window in the first stage of decomposition in both anaerobic and oxidative atmospheres, indicating that the process of volatile fuel generation does not require, or is not enhanced by oxygen in the environment. The rapid mass loss has been attributed to random chain scission with the loss of ether and carbonyl groups leaving most of the aromatic residue to crosslink and further decompose to carbonaceous char. The presence of filler increases the thermal stability of pure PEEK with the glass-fibre filled composite being the more thermo-oxidatively stable of the fibre-filled materials.

The presence of filler has a significant influence on the flammability of the materials; however the burning behaviour of PEEK and these two fibre-filled composites is very scenario dependent. This has been observed using a number of techniques and as a result, more is understood about the effects attributed to the presence of fillers. The PCFC shows differences in the ignition temperature between glass and carbon filled materials - 450GL30 has a slightly higher ignition temperature. However, in the cone calorimeter where heat transfer through the bulk of the solid is also important, 450GL30 ignites earlier than 450CA30. This is reversed in the PCFC where it is observed that 450CA30 ignites and begins losing weight at a lower temperature. The average heat release rate in the PCFC is $302 \mathrm{~W} \mathrm{~g}^{-1}$ for the virgin polymer, $195 \mathrm{~W} \mathrm{~g}^{-1}$ for the carbon fibre-filled composite and 232 $\mathrm{W} \mathrm{g}^{-1}$ for the glass fibre-filled composite. The ignition temperature of all three polymers is between $611^{\circ} \mathrm{C}$ and $616^{\circ} \mathrm{C}-$ being slightly lower for the unfilled material.

The burning behaviour of the fibre-filled composites also shows differences in the LOI tests. The carbon fibre-filled composites curl in on themselves whilst glass-fibre filled composites twist round themselves - the former being a more effective method for enclosing a flame and resulting in selfextinguishing behaviour, although may have no effect in real fire behaviour. 
Differences are noted between the filled and unfilled samples in the UL-94 tests, which are not noted when simply observing the V-ratings of the materials. The main difference is that for the unfilled polymer, the first flame application time $\left(t_{1}\right)$ is greater than the second $\left(t_{2}\right)$ - this is reversed for the filled polymers. This shows that unfilled PEEK forms a better protective layer on first ignition, where as the fibre-filled samples are easier to ignite after first ignition.

In both the cone calorimeter and the PCFC, the total heat released is reduced by the inert fraction of the fibre-filled composites. In the cone calorimeter, the glass fibre-filled composite has a lower average peak heat release rate than the carbon fibre-filled composite. Possible reasons for this are the enhanced structural integrity of the glass fibre char which forms a mechanically stable thermal radiation shield for the underlying composite. The combustion efficiency of the fuel gases in the flame for PEEK and its composites are similar and in the order of $90 \%$.

Conversely, the higher thermal conductivity of the carbon fibre-filled composite increases the materials' time to ignition giving, an average ignition delay time of 46 seconds when compared to the virgin polymer and 41 seconds compared to the glass fibre-filled composite.

\section{Acknowledgements}

The authors would like to thank the Engineering and Physical Science Research Council (EPSRC) for the award of a CASE PhD Studentship (No. 07001444). Additional gratitude is expressed to Victrex plc for technical support.

\section{References}

\footnotetext{
${ }^{1}$ Rose, J. B., and Staniland, P.A., Thermoplastic Aromatic Polyketones. European Patent 0001879B2, August 22 (1978).

${ }^{2}$ Hergenrother, P. M., Thompson, C. M., Smith Jr, J. G., Connell, J. W., Hinkley, J. A., Lyon, R. E., and Moulton, R., (2005), Flame Retardant Aircraft Epoxy Resins Containing Phosphorus. Polymer. 46(14), Pages 5012-5024.

${ }^{3}$ Morgan, A. B., Gagliardi, N. A., Price, W.A., and Galaska, M. L., (2009), Cone Calorimeter Testing of S2 Glass Reinforced Polymer Composites. Fire and Materials. 33(7), Pages 323-344.
}

${ }^{4}$ Matsui, J., (1995), Polymer Matrix Composites (PMC) In Aerospace. Advanced Composite Materials. 4(3), Pages 197-208.

${ }^{5}$ Day, M., Cooney, J. D., and Wiles D. M., (1989), "The Thermal Stability of Poly(Aryl Ether Ether Ketone) As Assessed By Thermogravimetry", Journal of Applied Polymer Science, 38(2), 323-337.

${ }^{6}$ Cole, K. C., and Casella, I. G., (1992), "Fourier Transform Infrared Spectroscopic Study of Thermal Degradation in Films of Poly(Ether Ether Ketone)", Thermochimica Acta, 211, 209-228.

${ }^{7}$ Cole, K. C., and Casella, I. G., (1993), “Fourier Transform Infrared Spectroscopic Study of Thermal Degradation in Poly(Ether Ether Ketone) - Carbon Composites", Polymer, 34(4), 740-745.

${ }^{8}$ Hay, J. N., and Kemmish, D. J., (1987), "Thermal Decomposition of Poly(Aryl Ether Ketones)", Polymer, 28, 2047-2051. 
${ }^{9}$ Tsai, C. J., Perng, L. H., and Ling, Y. C., (1997), “A Study of Thermal Degradation of Poly(Aryl-Ether-EtherKetone) using Stepwise Pyrolysis/Gas Chromatography/Mass Spectrometry", Rapid Communications in Mass Spectrometry, 11, 1987-1995.

${ }^{10}$ Naffakh, M., Ellis, G., Gomez, M., and Marco, C., (1999), "Thermal Decomposition of Technological Polymer Blends. 1. Poly(Aryl Ether Ether Ketone) with a Thermotropic Liquid Crystalline Polymer", Polymer Degradation And Stability, 66(3), 405-413.

${ }^{11}$ Nandan, B., Kandpal, L., and Mathur, G. N., (2002), “Poly(Ether Ether Ketone)/Poly(Aryl Ether Sulphone) Blends: Thermal Degradation Behaviour", European Polymer Journal, 39(1), 193-198.

${ }^{12}$ Huo, R., Luo, Y., Liang, L., Jin, X., and Karasz, F. E., (1990), "Kinetic Studies on Thermal Degradation of Poly(Aryl Ether Ether Ketone) and Sulphonated Poly(Aryl Ether Ether Ketone) by Thermogravimetry", Journal Of Functional Polymers, 4, 426-433

${ }^{13}$ Nam, J. D., and Seferis, J. C., (1992), “Generalised Composite Degradation Kinetics for Polymeric Systems under Isothermal and Nonisothermal Conditions", Journal of Polymer Science, 30(5), 455-463.

${ }^{14}$ Day, M., Cooney, J. D., and Wiles, D. M., (1989), "The Kinetics of the Oxidative Degradation of Poly(ArylEther-Ether-Ketone) (PEEK)", Thermochimica Acta, 147(1), 189-197.

${ }^{15}$ Day, M., Sally, D., and Wiles, D. M., (1990), "Thermal Degradation of Poly(Aryl-Ether-Ether-Ketone): Experimental Evaluation of Crosslinking Reactions”, Journal of Applied Polymer Science, 40, 1615-1620.

${ }^{16}$ Day, M., Cooney, J. D., and Wiles D. M., (1990), "The Thermal Degradation of Poly(Aryl Ether Ether Ketone) (PEEK) as Monitored by Pyrolysis-GC/MS and TG/MS", Journal of Analytical and Applied Pyrolysis, 18, 163-173.

${ }^{17}$ He, J., Duan, X., and Wang, Z.-X., (1997), "Study on the Kinetics And Mechanism of Thermal Degradation of PEEK by Temperature Programmed Decomposition", Acta Chimica Sinica, 55(12), 1152-1157.

${ }^{18}$ Perng, L. H., Tsai, C. J., and Ling, Y. C., (1999), “Mechanism and Kinetic Modelling of PEEK Pyrolysis by TG/MS", Polymer, 40, 7321-7329.

${ }^{19}$ Yao, F., Zheng, J., Qi, M., Wang, W., and Qi, Z., (1991), "The Thermal Decomposition Kinetics of Poly(EtherEther-Ketone) (PEEK) and its Carbon Fibre Composite", Thermochimica Acta, 183, 91-97.

${ }^{20}$ Zhang, H., (2004), Fire-Safe Polymers and Polymer Composites. US Department Of Transport. Report Number: DOT/FAA/AR-04/11. Federal Aviation Administration.

${ }^{21}$ Friedman, R., Friedman, J., and Linville, L., (2003) Principles of Fire Protection Chemistry and Physics: Part II Fire Protection Chemistry and Physics. Chapter $10-$ Fire Characteristics: Solid Combustibles. $3^{\text {rd }}$ Edition. Jones and Bartlett Publishers, London, UK.

${ }^{22}$ Lyon, R. E., and Walters, R., (2002), A Microscale Combustion Calorimeter. US Department of Transport. Report Number: DOT/FAA/AR-01/117. Federal Aviation Administration.

${ }^{23}$ Babrauskas, V., and Peacock, R. D., (1992), Heat Release Rate: The Single Most Important Variable in Fire Hazard. Fire Safety Journal. 18(3), Pages 255-272.

${ }^{24}$ Hugget, C., (1980), Estimation of the Rate of Heat Release by Means of Oxygen Consumption Measurements. Fire and Materials. 4(2), Pages 61-65.

${ }^{25}$ Babrauskas, V., (1982), Development of the Cone Calorimeter. A Bench-Scale Heat Release Rate Apparatus Based on Oxygen Consumption (NBSIR 82-2611). US National Bureau of Standards. 
${ }^{26}$ Lyon, R.E., and Walters, R. N., Microscale Combustion Calorimeter, US Patent 5,981,290, November 9 (1999).

${ }^{27}$ Schartel, B., Pawlowski, K. H., and Lyon, R. E., (2007), Pyrolysis Combustion Flow Calorimeter: A Tool to Asses Flame Retarded PC/ABS Materials? Thermochimica Acta. 462(1-2), pages 1-14.

${ }^{28}$ Lu, H., and Wilkie, C. A., (2010), Synergistic Effect of Carbon Nanotubes and Decabromodiphenyl Oxide $/ \mathrm{Sb}_{2} \mathrm{O}_{3}$ in Improving the Flame Retardancy of Polystyrene. Polymer Degradation and Stability. 95(5), pages 564-571.

${ }^{29}$ Hull, T. R., and Stec, A. A., (2009), Polymers and Fire. Chapter 1. In Hull, T. R., and Kandola, B., K., (editors) Fire Retardancy of Polymers: New Strategies and Mechanisms. Royal Society of Chemistry, UK.

${ }^{30}$ ASTM D7309: 2007. Determining Flammability Characteristics of Plastics and Other Solid Materials Using Microscale Combustion Calorimetry.

31 ISO 4589: 1996. Plastics - Determination of Burning Behaviour by Oxygen Index. Part 2: AmbientTemperature Test.

32 BS 60695: 1999. Fire Hazard Testing. Part 11-10 Test Flames - 50 W Horizontal and Vertical Flame Test Methods.

${ }^{33}$ ASTM Standard E 1354-04a. Standard Test Method for Heat and Visible Smoke Release Rates for Materials and Products Using an Oxygen Consumption Calorimeter, ASTM International, West Conshohocken, PA, 2007.

${ }^{34}$ Patel, P., Hull, T. R., McCabe, R. W., Flath, D., Grasmeder, J., and Percy, M., (2010), Mechanism of Thermal Decomposition of Poly(Ether Ether Ketone) (PEEK) From a Review of Decomposition Studies. Polymer Degradation and Stability. 95(5), pages 709-718.

${ }^{35}$ Lyon, R. E., and Janssens, M. L., (2005), Polymer Flammability. US Department Of Transport. Report Number: DOT/FAA/AR-05/14.

${ }^{36}$ Morgan, A.B., and Bundy, M., (2007), Cone Calorimeter Analysis of UL-94 V-Rated Plastics. Fire and Materials. 31, pages 257-283

${ }^{37}$ Lyon, R. E., and Quintiere, J. G., (2007), Criteria for Piloted Ignition of Combustible Solids. Combustion and Flame. 151, pages 551-559.

${ }^{38}$ Quintiere, J. G., (1997), Principles of Fire Behaviour. Delmar. Albany, NY.

${ }^{39}$ Drysdale, D., (1999), An Introduction to Fire Dynamics. $2^{\text {nd }}$ Edition. John Wiley \& Sons, Chichester.

${ }^{40}$ Lyon, R. E., (2002), Ignition Resistance of Plastics. Lewin, M., (editor) Recent Advances in Flame Retardancy of Polymers. Volume 13. Business Communications Co. Inc. Norwalk. 14-25.

${ }^{41}$ Schartel, B., and Hull, T.R., (2007), Application of Cone Calorimetry to the Development of Materials with Improved Fire Performance. Fire and Materials. 31, pages 327-354 